\title{
A Critical Review of Evolution of Cancer Registration in India
}

\section{Murali Dhar*}

Department of Population Policies and Programmes, International Institute for Population Sciences, India

Submission: November 30, 2017; Published: January 10, 2018

*Corresponding author: Murali Dhar, Department of Population Policies and Programmes, International Institute for Population Sciences, Mumbai-400088, India, Email: m.dhar@iips.net

\section{Demographic Profile}

Let me start with the beginning of the $20^{\text {th }}$ century when the population of India was 238 million. The Crude Birth Rate and Crude Death Rate both were about 40-50 per 1000 population resulting in a stable population and putting India into first stage of Demographic Transition. Two important problems of the population were high fertility and high mortality. The first one was a major public health issue resulting in poor maternal and child health. However, this was hidden in the problem of high infant and child mortality because in order to end up with a few children ultimately, couples needed to have more children. Thus focus area of the government was only mortality control, especially the high infant and child mortality. Moreover, the life expectancy was very low. Hardly any person used to survive beyond 40-50 years of age. Obviously, there was no scope for non-communicable diseases in general and cancer in particular.

By the middle of the $20^{\text {th }}$ century the population reached 361 million, increasing about one and a half times compared to the beginning of the century. The crude death rate declined to about 25 per 1000 . However, the crude birth rate remained above 40 per 1000 resulting in an increased growth rate and putting India into second stage of demographic transition. Although mortality declined substantially, it was still on the higher side, especially the infant and child mortality. In addition, population or fertility control also got the attention of the Indian Government. As a result, India became the first country to launch a national family planning programme in 1952. In view of the improvement in life expectancy and more people surviving beyond 40-50 years of age, non-communicable diseases including cancer may have started arising as a public health issue but only slightly, still not catching the attention of the responsible authorities.

Towards the end of the 20th century the population became 1029 million, increasing about threefold during the second half of the century. The crude birth and death rates both declined substantially resulting into higher growth rate (about 2\%). Total fertility rate declined to three per woman. Infant and child mortality rates declined quite substantially, however still being on the higher side. Due to increase in life expectancy coupled with changes in life style, non-communicable diseases including cancer also became an important public health problem (Table 1) [1-6].

Table 1: Demographic profile of India in the $20^{\text {th }}$ century [1-6]

\begin{tabular}{|c|c|c|c|}
\hline \multirow{2}{*}{ Demographic characteristics } & \multicolumn{3}{|c|}{ Twentieth century } \\
\cline { 2 - 4 } & Beginning & Middle & End \\
\hline Population (in millions) & 238 & 361 & 1029 \\
\hline Crude birth rate (per 1000) & 48 & 41 & 25 \\
\hline Total fertility rate (per woman) & $>6$ & 6 & 3 \\
\hline Crude death rate (per 1000) & 48 & 25 & 8 \\
\hline $\begin{array}{c}\text { Infant mortality rate (per 1000 live } \\
\text { births) }\end{array}$ & $>200$ & 190 & 68 \\
\hline $\begin{array}{c}\text { Under-five mortality (per 1000 live } \\
\text { births) }\end{array}$ & $>350$ & 300 & 95 \\
\hline Life expectancy at birth (years) & 20 & 40 & 65 \\
\hline
\end{tabular}

Presently the population is about 1,300 million. During the last 15 years or so, there is further improvement in almost all the indices. The crude birth rate however is still on the higher side resulting into an average of 2.5 children per woman. The population has been increasing which is projected to become somewhat stationary in the next 10 to 20 years. Some of the states like Kerala have already recorded below replacement level fertility, meaning less than two surviving children. In addition, there has been rapid health transition with the rising burden of non-communicable diseases. The burden of communicable diseases, although declined substantially, is far from over and newly emerging problems also get added. Thus India has multidimensional tasks on the population policy front. These are: maternal and child health, existing communicable diseases, newly emerging communicable diseases, non-communicable diseases, senior citizen management, etc. With this demographic 
overview of the country, let me now highlight the evolution of cancer registration in India.

\section{Evolution of Cancer Registration}

Although cancer is known in Indian history from Vedic times, no data on cancer were available in India until 1963 when a limited period cancer survey was undertaken in the Manipuri district of Uttar Pradesh by the Indian Cancer Society, Mumbai. Following the survey, the Indian Cancer Society established a population-based cancer registry in Mumbai in the same year [7]. Subsequently, with the idea of getting a picture of cancer pattern in whole of Maharashtra, three satellite registries of the Mumbai registry were established; at Pune in 1972 [8], at Aurangabad in 1978 [9] and at Nagpur in 1980 [10]. Probably taking a clue from the Indian Cancer Society, the Gujarat Cancer Research Institute also established a population-based cancer registry for Ahmedabad city in 1980 [11].

Despite a few decades of cancer registration history in India and reliable data for Mumbai, Pune, Aurangabad, Nagpur and Ahmedabad respectively from 1964, 1972, 1978, 1980 and 1983, there were no data at the national level or data that can be extrapolated at the national level until the early 1980s. Realising the growing problem of cancer due to the control of communicable diseases and the resultant increase in life expectancy and the lack of information on the magnitude and pattern of cancer in India, the Indian Council of Medical Research (ICMR), a premier medical research institution in India, initiated a national network of cancer registration, namely the National Cancer Registry Programme (NCRP), in 1980 with the objectives of

a) Generating authentic data on the magnitude and pattern of cancer problem,

b) Undertaking epidemiological investigations and institute control measures,

c) Promoting human resource development in cancer registration and epidemiology [12].

\section{Generation of authentic data on cancer in India}

To fulfil the first objective, a few cancer registries were established to start with and expanded to the extent possible during the course of time. NCRP started initially with 3 PBCRs in Mumbai, Bangalore and Chennai and 3 HBCRs in Chandigarh, Dibrugarh and Thiruvananthapuram starting data collection from 1982. Later in 1984, three more HBCRs started in the places where PBCRs were already functioning. During the late 1980's and early 1990's three more PBCRs were added; in Delhi, Bhopal and Barshi which is a rural taluk of Solapur district of Maharashtra. Later on however, one HBCR in Chandigarh closed. Thus, India had 6 PBCRs and 5 HBCRs till early this century. These 6 PBCRs use to cover 3.3 per cent of India's total population and $0.06 \%$ of the rural population. During the last 10 to 15 years, there has been considerable expansion of cancer registration in
India, scientific basis for the same however, appear lacking.

Currently, there are 29 PBCRs and 17 HBCRs, the newer registries however are still in infancy or childhood stage. NCRP, which started as a long term project of ICMR, is now part of a full-fledged institute of ICMR called National Centre for Disease Informatics and Research which includes addressing cardiac disease, diabetes and stroke also. An NCD survey also has been undertaken by NCDIR. All these expansions and new initiatives however are still at the early stages of development or execution.

\section{Human resource development and epidemiological studies in India}

The second objective of the NCRP was to undertake epidemiological studies utilizing NCRP data and other resources available with the PBCRs and HBCRs. The third objective, which was somewhat parallel to the second one in achievement, was to create a human resource in the cancer registration and epidemiology [12]. In order to meet the second objective, the third was required to be achieved at least substantially. Therefore, efforts to create human resource development somewhat preceded the occurrence of epidemiological studies. It was in 1989, when the Indo-Finland collaboration program was established with the objective of personnel associated with cancer registration and epidemiology in India receiving training in Epidemiology in Finland with financial assistance from the Finnish side. This was the seed sown for the development of experts in cancer epidemiology in India that has blossomed into a big tree during more than two and a half of the last decades. In addition to Indo-Finland collaboration, there have been many other programs and fellowships playing a role in the development of human resources in India, most prominently of them being the Summer School Program of IARC and ICRETT fellowship of UICC. A vast pool of human resources thus generated has been engaged in cancer registration and research as well as cancer control activities in different regions of the country. In addition, they have also been instrumental in expansion of cancer research activities and have contributed to training other staff in the different cancer registries.

Although there may not have been optimum utilization of raw data potentially due to non-availability of the same in the public domain, there have been many epidemiological studies utilizing the HIS-related infrastructure available with individual registry institutions. Some prominent examples of them are casecontrol studies looking into etiological factors of many cancers and survival studies dealing with the prognosis and associated factors of many cancers. A detailed and exhaustive account of those studies is beyond the purview of this study. However, I discuss them in brief in the following sections just to highlight the achievement of the second objective of NCRP. In addition to the analytical studies, there have been many descriptive epidemiological studies utilizing information from published reports of NCRP dealing with methodological developments, projection of national burden, pattern, trend and geographic 
variation in the occurrence of cancer [13-22].

\section{Case-Control Studies}

Case control studies are an important tool in the assessment of etiological factors for NCDs in general and cancer in particular due to relatively rare occurrence and common exposure factors. These studies are especially useful in the setup of developing countries where the conduct of long duration cohort studies is really difficult due to inadequate HIS and scarce financial resources. There were rare examples of case control studies in India prior to the establishment of the NCRP. Following the NCRP establishment, however, there has been boom in case control studies dealing with the assessment of cancer etiological factors in India. A series of case control studies has been conducted as a $\mathrm{PhD}$ thesis research under the DPPH program with Indo-Finnish collaboration. Different cancer sites covered in these researches were esophageal cancer [23], gastric cancer [24], contra lateral breast cancer [25], childhood hematological malignancies [26], breast cancer [27], prostate cancer [28] and pharyngeal cancer [29].

In addition to the above academic dissertations published by the University of Tampere, there have been many case control studies conducted under the auspices of the NCRP and published in reputed journals. A few of them, for example, are as follow:

a) Four case-control studies in Mumbai dealing with stomach cancer [30], colorectal cancer [31], lung cancer [32] and prostate cancer [33].

b) Two case-control studies in Bangalore dealing with ovarian cancer [34] and esophageal cancer [35].

c) A case control study in Chennai dealing with stomach cancer [36].

d) A case-control study in Delhi dealing with gallbladder cancer [37].

\section{Survival Studies}

Knowledge of survival is essential in the community level management of a disease. Its knowledge over a period of time helps in monitoring and improving the levels of prognostic factors in the population. In addition, survival duration also helps in deriving various indices of the burden of disease, like, disability adjusted life years, healthy life expectancy, etc. Conducting of population-based study of cancer survival is a difficult task in developing countries due to the non-existence of health information systems and the resultant poor follow-up of patients. Therefore, there have been only a limited number of population-based survival studies in India. First populationbased cancer survival study for a selected site of cancer emerged in mid-1990s [38] as a result of the initiative taken by IARC, Lyon, France for a multi-national collaborative study on cancer survival in developing countries in 1994 by Sankaranarayanan et al. [39]. Later on, there have been few more population-based cancer survival studies in India mostly with the support from international agencies $[40,41]$.

There are many reasons for only sporadic survival studies in India described in detail somewhere else [42]. These include time and finances required to conduct the study, the problem of loss to follow-up and also the time gap between the year of diagnosis of patients and the availability of results on the survival. In view of these difficulties, Dhar et al. [19] proposed an indirect method for study of cancer survival utilizing the current data on cancer incidence and morbidity. In addition, there have been a few methodological studies in India dealing with the biases in survival estimated due to substantial losses to follow-up [4345]. The time gap problem was realized even in the developed world, also prompting Brenner \& Gefellar [46] to come out with a new method called 'period analysis' to overcome the same. This method is based on the concept of period monitoring of the subjects instead of the usual practice of cohort monitoring.

\section{Validity of Outputs of Cancer Registration in India}

Broadly, there are three dimensional outputs of cancer registration in India. One, reports of individual cancer registries and consolidated reports of the same from central coordinating unit, two, analytical studies carried out by the personnel associated with NCRP utilizing technical expertise and resources available with registries, and three, descriptive studies dealing with burden, pattern and trend of cancer in the country. There does not appear any problem as far the validity of first two is concerned. Because, first one just reports the situation in the respective registry area without any generalization beyond and second one pertains to case-control and survival studies following established standard protocols. Third category of output of cancer registration in India deals mainly with the generalization of risk, pattern, trend observed in the cancer registry areas to the whole country. Few examples of this are: cancer has become one of the ten leading causes of death in India, about 1 million new cases and half million deaths occur annually due to cancer, it is estimated that there are about 3 million persons with cancer at any given point of time, and, cancers of oral cavity and lung in males and cervix and breast in females account for roughly half of all cancer deaths in India.

The obvious question here is, whether the above statements are valid? Nobody has the answer as these statements are based on generalizations of observations from a few registries to India without any validation exercise. The only justification is: this is the best picture available. Given the diversity in India, the validity of these statements is always under doubt. India has great diversity in almost all the factors associated with cancer. Most important factor is tobacco consumption. Let's have a look at the diversity in the prevalence of tobacco consumption. Figure 1 provides a pictorial presentation of prevalence of tobacco use by men in India. It is evident that the prevalence varies from as low as less than $35 \%$ to a high of over $65 \%$. Similarly, there is a great deal of variation in life style and dietary practices. Another factor that may highly influence the validity is urban/rural divide 
of the country. Although, majority of Indian population lives in rural area, most of the PBCRs especially those established in the beginning are in urban areas. Environmental and physical activity related conditions are completely different among the people living in urban and rural areas.

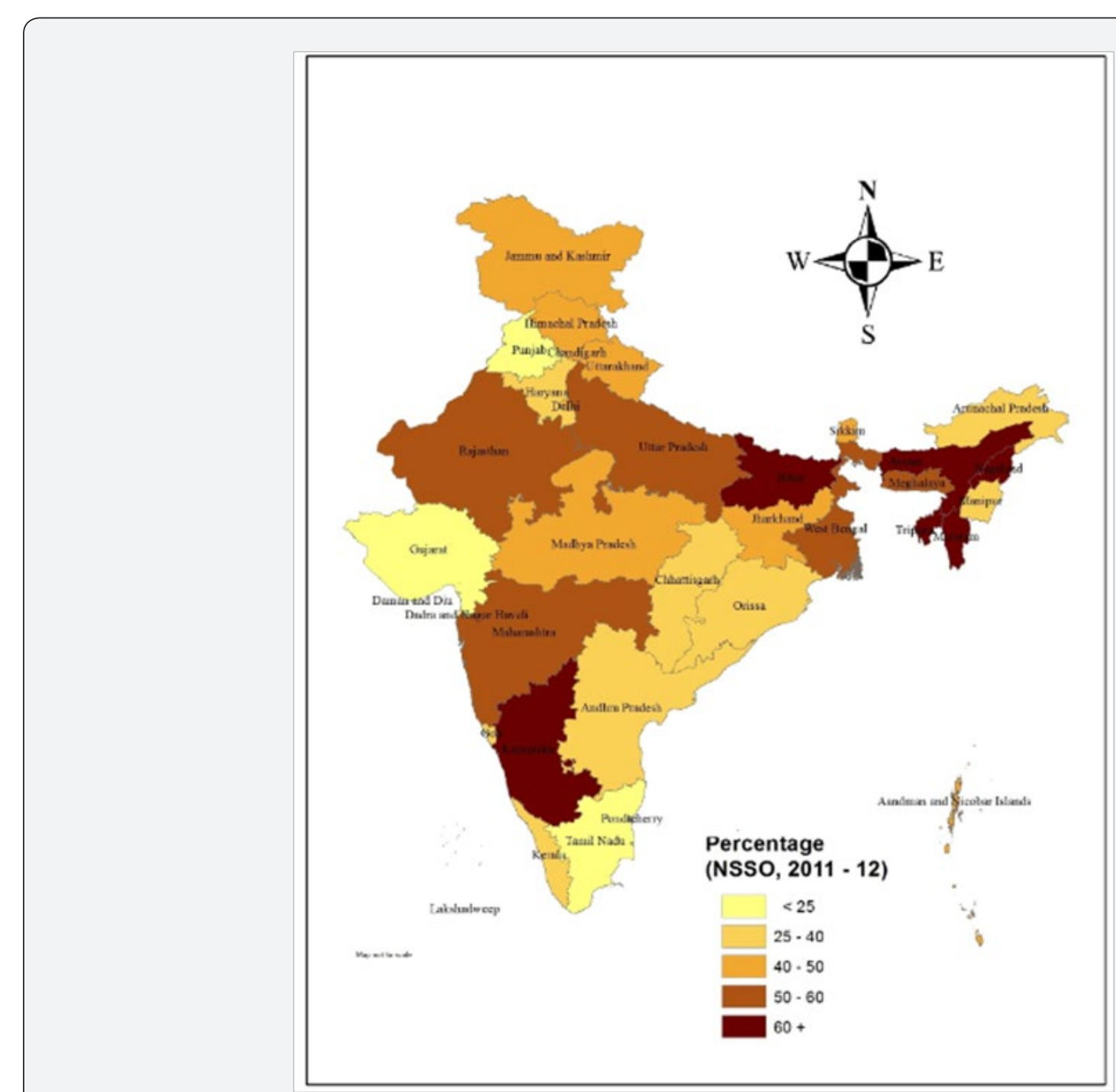

Figure 1: Prevalence of any tobacco use in India, 2011-12.

When we are not certain about validity, then what is the solution? The ideal one is to have a national level population based cancer registry: this is next to impossible given the status of the health information system and the resources required. The next best solution is to establish cancer registries in very carefully chosen areas accounting for etiological diversity in the country: This is very difficult in practice. To give a feel of the extent of difficulties involved in materializing above options, let me highlight the process of data collection and the difficulties in the same.

\section{Process of Data Collection in Indian PBCRs}

The process of cancer registration in India is active and therefore, cancer registry personnel visit all the potential sources of cancer patients or their records and collect data on a standard pro-forma. The first step in the process of data collection after establishing a PBCR is to identify and list all potential sources of cancer cases inside as well as outside the registry area. This list needs to be updated regularly, and it may include a cancer hospital, if any, general hospitals, private hospital, nursing homes, pathology labs and corporation in the registry area. From outside the registry area, one may include in the list those reputed cancer hospitals where the patients from the registry area may potentially go for diagnosis and/or treatment. Staff members of the registry personally visit the potential sources regularly to interview all identified cancer patients and also those under investigation. As a result of such data collection from different sources, one and the same patient is sometimes found to be registered from multiple sources. Care is taken to see that multiple entries for the same patient are not made in the 
records. This is done by matching different combinations of the fields, like, name, age, sex, ICDO and ICD9/10 codes etc. On the other hand, in some instances, complete or maximum possible information is obtained by combining the data from two or more sources. Another important thing to ensure about a case is its residential status. Pro-forma has a question on the duration of stay in the present place of residence. Using this information, all the patients with duration of stay less than one year are considered as non-resident in the registry area and therefore removed from the data set. After ascertaining the removal of duplicates and non-residents, the whole data set is subjected to standard quality control checks and then transmitted to the Coordinating Unit (CU). The CU then subjects the data set received from the registry to more extensive quality control checks and finalises the same for analysis and reporting. The whole process of data collection in Indian PBCRs described above has also been depicted diagrammatically in Figure 2.

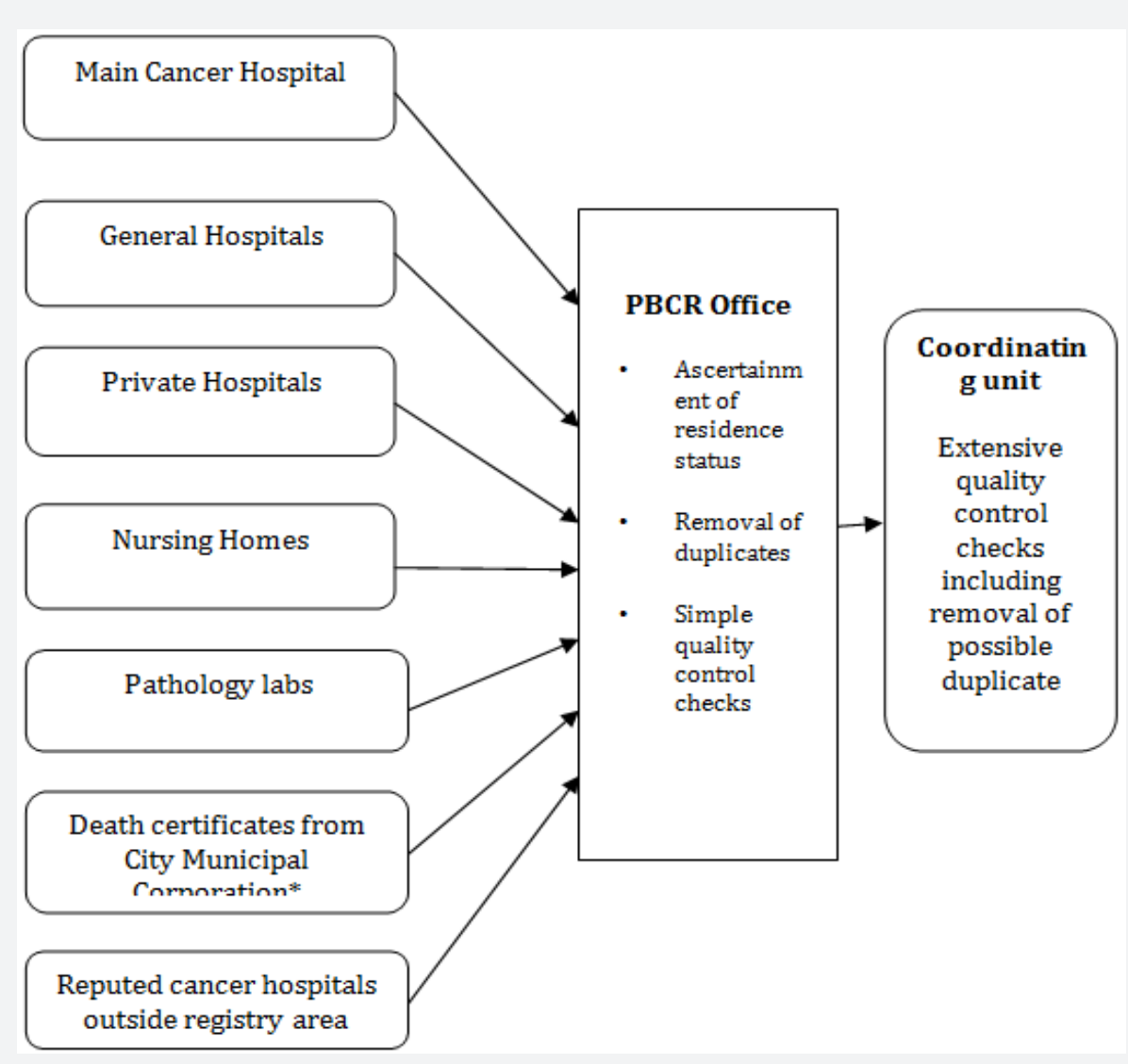

Figure 2: Diagrammatic presentation of data collection process in Indian PBCRs.

\section{Difficulties in Operating a PBCR}

As defined earlier, a PBCR needs to register each and every case (satisfying the specific case definition) arising in a defined geographic area. To do this, unlike developed countries, most (if not all) of the developing countries do not have an advanced health information system (HIS) and unique identification number (UID) that identifies each and every individual of the country by a unique number. In fact, India has a UID called AADHAR issued by Unique Identification Authority of India (UDAI). Its full coverage however is yet to be ascertained let apart linking to health, morbidity and mortality records. The lack of an efficient HIS affects the coverage of a PBCR. On the other hand, the lack of UID makes ruling out the duplicate registrations on the same patient difficult, thereby affecting the quality of data. In developing countries, the method of data collection is active. As a result, we have to depend on the following sources to attempt registering all the cases of a PBCR. HBCR in the PBCR area, if any, General hospitals, Private hospitals, Nursing homes, Cancer centers, General practitioners, Screening programmes, Death certificates (Corporation, cremation canters, burial grounds records, etc.), and, Pathology labs.

A PBCR has to maintain an up-to-date list of all the above sources, and registry personnel should visit them at a regular interval. This requires huge resources in terms of money and time, which makes the functioning of a registry at the national level next to impossible and delays the publication of reports pertaining to a particular year. Another problem with the PBCR data, mostly due to the reasons explained above, is that clinical and treatment details are not available for a substantial number of cases. Hence, there is always a thrust for the alternative options. 
Now, when the ideal options appear impossible or very difficult given the present health information system and the financial resources, what are the potential or indirect alternatives? A thorough acquaintance with cancer registration and related activities in India hints at two potential alternatives; one use of HBCRs for estimating cancer pattern, and two, development of atlas of cancer in India. Let us have a close look at these two alternatives.

\section{Hospital-based cancer registries (HBCRs)}

Unlike PBCRs, HBCRs register data on the patients coming to particular hospital irrespective of their place of residence. Being hospital-based, HBCRs are able to provide relatively better data of diagnostic, clinical and treatment details. Therefore, typical uses of HBCRs are related to patient care in a hospital Established and documented uses of the HBCR are as follows [47-49]. To assess patient care, to participate in clinical research to evaluate therapy, to provide an idea of pattern of cancer in the area and to help to plan hospital facilities.

HBCRs are useful mainly in clinical research relating to the first two uses listed above. We may term these as the direct uses of HBCR. According to a survey conducted by Howard et al. [50], the use of HBCR data to evaluate the quality of cancer care and patient outcomes was not routine. Their conclusion was based mainly on the findings pertaining to less utilisation of HBCR data for cancer care and patient outcome research. They also studied the relationship of HBCR data use to geographic and logistical factors and concluded that increasing the availability of trained registrants, specialised cancer registry software and maximising completeness of data, could potentially increase their usefulness as tools to improve cancer care. There are many uses of HBCR data as described above. Well accepted uses are: to assess patient care, to participate in clinical research to evaluate therapy, and to help plan hospital facilities. In addition, there are some potential uses that require validation. These uses are based on the generalisation of relative frequencies (proportion of a particular site relative to all sites) at the population level. There are examples of generalisation of hospital data at the population level in India [51-53] as well as abroad [54-56].

Dhar \& Nandakumar [51] utilised HBCR data to study the urban rural differences in cancer patterns. They combined the data of HBCRs located in Bangalore, Chennai and Thiruvannanthapuram, in the southern part of the country and divided the data into urban and rural by matching the pin codes of permanent addresses of the patients. They observed that the proportion of leading sites of cancer as well as the proportion of advanced and localised cancer did show some variations between urban and rural areas. In a report from Mumbai, India [52], an attempt has been made to interpret the data of HBCR for different areas of Maharashtra. While ascertaining the leading sites in different regions, the report states that the observed differences in relative frequencies need further scrutiny.

\section{Atlas of cancer in India}

In view of the difficulties with PBCR described above, the thrust has been on finding an alternative to PBCR and the concept of an 'Atlas of cancer' is one of them. It was observed in PBCR data that $85-90 \%$ of cancers had a microscopic diagnosis. This meant theoretically that if we are able to include all the potential sources of microscopic diagnosis in our programme, we can be reasonably sure of capturing 85 to $90 \%$ of cancer cases in the country. This was the technical basis for starting the WHO funded project titled 'Development of an atlas of cancer in India' $[53,57]$. The objectives of this project were, to obtain an overview of cancer patients in different parts of the country, and, to calculate estimates of cancer incidence wherever feasible.

Data were obtained from all the sources of microscopic diagnosis of cancer, who gave their consent for participation in the project. Quality control exercises, mainly elimination of duplicates, were carried out. Utilizing the data on place of residence, the cases were divided to arrive at the number of incident cancer cases by district of residence. Subsequently, these numbers were divided by the population of the district to obtain the 'minimum cancer incidence rate' (MCIR) for that state. The results of the project were presented diagrammatically, also showing the MCIR for different districts of the country.

Theoretically, the uses of ATLAS data are identical to those of PBCRs. Practically however; the validity of the uses depends upon the tenability of the assumptions involved. The uses of ATLAS data are similar to the uses of PBCR data if ATLAS is able to capture 80 to $90 \%$ of cases, i.e., MCIR reported by ATLAS is $80 \%$ to $90 \%$ of the true incidence rate. However, the uses will be valid under the assumption that the deficit in ATLAS data is proportionally distributed among different primary sites of cancer. Under these assumptions, ATLAS data may be used to find the risk of different forms of cancer and the patterns and trends therein.

\section{Summary}

Till third quarter of last century, India concentrated its focus mainly on high mortality particularly infant and child mortality followed by population control mainly through family planning programme. Policies were based on the theory that population control leads to development. Subsequently, it was established that it is the development that is remedy of all the problems including population growth. As a result, the focus shifted to development and health which continues till date. Thus NCD in general and cancer in particular did not find considerable focus in the policies. Cancer however seems to have got its due attention at almost the right time. The expansion, uses of data for research, control measures initiated however, are subject to scrutiny.

Overall health information system is known to be inadequate not only in India but in the developing countries in general. There has been a lot of development on this front in the country over 
last 3 to 4 decades. However, there are different organizations/ institutions dealing with the health aspects they are associated without adequate coordination among them. This causes lack of exchange of knowledge, technology and other potentially exchangeable resources. These problems with the health information in general have resulted as a hurdle in optimum utilization of health information resources. Therefore, those associated with health and family welfare in the country may be recommended to integrate the scattered sources of health information under the umbrella of 'Health Information System in India'. In fact, there has been some conceptual development in this direction; however, the same has been confined to specific programme (s).

National cancer registry programme in India started with 3 PBCRs and HBCRs each and expanded to about 30 PBCRs. Thus there has been considerable expansion of cancer registration in India, especially in case of PBCRs, over last three and a half decades. The expansions however appear to have happened based on more of feasibility and unknown criteria than scientific rationale. There is clustering of PBCRs in north-east region and southern part of the country. About thirty PBCRs covering about $10 \%$ of country's population could have yielded a good representative sample if the expansions were on the scientific basis. Therefore, those associated with cancer control planning in the country may be recommended to strengthen cancer information by opening up more PBCRs accounting for cancer etiological diversity in the country.

Non-availability of the data collected by NCRP in the public domain may potentially be a reason for the less utilization of the data for research purposes. On the other hand, there has been extensive utilization of data from other sources of health information (like, Census, SRS, NFHS, DLHS, etc.) perhaps due to their availability in public domain. Therefore it may be recommended to make the HBCR and PBCR data available in the public domain. Another thing observed is that the time periods for reporting of consolidated data from HBCRs and PBCRs are different (barring few exceptions). This may be among the reasons for the lack of research integrating HBCR and PBCR data together. Therefore, it may be recommended that as far as possible, consolidated data of HBCRs and PBCRs is reported for the same year.

In view of the difficulties in establishing and maintaining a PBCR, there have been some efforts to find the indirect way of assessing cancer pattern at the population level. Two visible ways are use of HBCR data and development of atlas of cancer. Use of first way has been limited whereas that of second one has been quite wide. Validity of both however is subject to examination. Repeated use of second one seems to be on the perceived validity rather than any concrete validation. A recent study by Dhar [22] however, has found that none of these two ways is valid in assessing cancer pattern at the population level. To validate the findings of this study, more detailed research with raw data may be recommended. At the same time however, while using new technology, one has to be certain about its validity especially when substantial financial resources are spent by a low/middle income country.

To conclude, looking at the health indicators and cancer registration activities over last more than a century, country has made great achievements with the limited resources and set many examples in the process to be potentially imitated by other developing countries. Comparing with the developed world however, there are a lot to be done in future. Use of the limited resources in a carefully chosen scientific way should be the key to bridge the gap of the country with developed world.

\section{Acknowledgement}

Author is grateful to Ms. Catarina Stahle-Nieminen, International Coordinator, University of Tampere, Finland, for her help in the language revision of author's introductory lecture during his Doctoral defence. Author is thankful to Mr. Kamalesh Kumar Patel \& Mr. Jang Bahadur Prasad, Research Scholars at IIPS, for their help in finalizing the manuscript.

\section{References}

1. Ram F, Namboodiri K, Ram U (1995) Fertility Transition in India Report prepared for the rock feller foundation, New York, USA.

2. Bhat MP (1987) Mortality in India: levels, trends and patterns, unpublished Ph.D. Dissertation, University of Pennsylvania, Philadelphia, USA.

3. Gupta DP (1971) Estimation of demographic measures for India 1881-1961, based on census age distributions. Popul Stud (Camb) 25(3): 395-414.

4. Risley HH, Gait EA (1903) Report on the Census of India, 1901. Superintendent of Government Printing, Calcutta, India.

5. RGI (Registrar General of India) (1955) Census of India, 1901.New Delhi, India.

6. RGI (Registrar General of India) (2011) Census of India, 2011.New Delhi, India.

7. Jussawalla DJ, Deshpande VA (1966) Cancer in Greater Bombay-1964. Mumbai Cancer Registry, Indian Cancer Society, Mumbai, India.

8. Jussawalla DJ, Sathe PV, Yeole BB, Natekar MV (1979) Cancer incidence in Poona city Agglomeration. Mumbai Cancer Registry, Indian Cancer Society, Mumbai, India.

9. Jussawalla DJ, Sathe PV, Yeole BB, Natekar MV (1984) Cancer incidence in Aurangabad city. Ind J Cancer 21(2): 55-62.

10. Jussawalla DJ, Gandhe ML, Yeole BB, Natekar MV (1987) Cancer Morbidity and Mortality in Nagpur city. Mumbai Cancer Registry, Indian Cancer Society, Mumbai, India.

11. Patel TB (1986) Biennial Report 1984-85, Cancer registry for Ahmedabad urban agglomeration. Gujarat Cancer and Research Institute, Gujarat, India.

12. NCRP (National Cancer Registry Programme) (1987) Code ManualHospital Cancer Registry. Indian Council of Medical Research, New Delhi, India.

13. Murthy NS, Juneja A, Sehgal A, Luthra UK (1990) Cancer projection by the turn of century. Indian J Cancer 27(2): 74-82.

14. Krishnamurthy S, Dhar M (1992) Cancer and other causes of childhood mortality in Bombay, India. Cancer 68(8): 1848-1853. 
15. Ram F, Dhar M (1992) A modified procedure for calculating person years of life lost. Janasamkhya 10(1-2): 1-12.

16. Yeole B (1997) Cancer in India in the year 2001. Acta Universitatis Tamperensis, University of Tampere, Tampere, Finland, Europe, 552.

17. Yeole BB, Kurkure AP (2003) An epidemiological assessment of increasing incidence and trends in breast cancer in Mumbai and other sites in India, during last two decades. Asian Pac J Cancer Prev 4(1): 51-56.

18. Yeole BB, Kurkure AP, Koyande SS (2006) Geographic variation in cancer incidence and its pattern in Maharashtra, 2001. Asian Pac J Cancer Prev 7(3): 385-390.

19. Dhar M, Lahiri S, Takiar R, Ashok NC, Murthy NS (2008) An indirect study of cancer survival in the context of developing countries. Asian Pac J Cancer Prev 9(3): 479-486.

20. Takiar R, Nandakumar A (2011) Estimating the burden of cancer. Natl Med J India 24(2): 69-71.

21. Swaminathan R, Shanta V, Ferlay J, Bray F, Sankaranarayan R (2011) Trends in cancer incidence in Chennai city (1982-2006) and statewide predictions of future burden in Tamil Nadu (2007-2016). Natl Med J India 24(2): 72-77.

22. Dhar M (2017) Estimation of cancer pattern by means of hospital-based cancer registries and pathology laboratory data. Acta Universitatis Tamperensis, University of Tampere, Tampere, Finland, Europe.

23. Ramesh C (1993) Oesophageal cancer: An epidemiological study in India. Acta Universitatis Tamperensis, Ser A, University of Tampere, Tampere, Finland, Europe.

24. Ravichandran K (1997) A hospital based case-referent study on gastric cancer in Madras. Acta Universitatis Tamperensis, 553. University of Tampere, Tampere, Finland, Europe.

25. Gajalakshmi CK (1997) Contralateral breast cancer in Madras, India. Acta Universitatis Tamperensis, University of Tampere, Tampere, Finland, Europe.

26. George J (1997) Childhood haematological malignancies in India. Acta Universitatis Tamperensis, Ser A, University of Tampere, Tampere, Finland, Europe.

27. Reddy KR (2004) Role of socioeconomic status and reproductive factors in breast cancer. Acta Universitatis Tamperensis, 1009. University of Tampere, Tampere, Finland, Europe.

28. Sunny L (2005) Prostate cancer: An epidemiological study in India Acta Universitatis Tamperensis, University of Tampere, Tampere, Finland, Europe.

29. Jayaram DJ (2017) Microscopically confirmed pharyngeal cancer in south India: An epidemiological case-control study. Acta Universitatis Tamperensis, University of Tampere, Tampere, Finland, Europe.

30. Rao DN, Ganesh B, Dinshaw KA, Mohandas KM (2002) A case-control study of stomach cancer in Mumbai, India. Int J cancer 99(55): 727 731.

31. Ganesh B, Talole SD, Dikshit R (2009) A case-control study on diet and colorectal cancer from Mumbai, India. Cancer Epidemiol 33(3-4): 189193.

32. Ganesh B, Sushma S, Monika S, Suvarna P (2011) A case-control study of risk factors for lung cancer in Mumbai, India. Asian Pac J Cancer Prev 12(2): $357-362$

33. Ganesh B, Saoba SL, Sarade MN, Pinjari SV (2011) Risk factors for prostate cancer: A hospital-based case-control study from Mumbai, India. Indian J Urol 27(3): 345-350.

34. Nandakumar A, Anantha N, M Dhar, Ahuja V, Kumar R, et al. (1995) A case-control investigation on cancer of the ovary in Bangalore, India. Int J Cancer 63(3): 361-365.
35. Nandakumar A, Anantha N, Pattabhiraman V, Prabhakaran PS, Dhar $\mathrm{M}$, et al. (1996) Importance of anatomical subsite in correlating risk factors in cancer of the oesophagus-report of a case-control study. Br J Cancer 73(10): 1306-1311.

36. Gajalakshmi CK, Shantha V (1996) Lifestyle and risk of stomach cancer: A hospital-based case-control study. Int J Epidemiol 25(6): 1146-1153.

37. Tyagi BB, Manoharan N, Raina V (2008) Risk factors for gallbladder cancer: A population-based case-control study in Delhi. Indian Journal of Medical and Pediatric Oncology 29(1): 16-26.

38. Nandakumar A, Anantha N, Venugopal TC, Sankaranarayanan R, Thimmasetty K, et al. (1995) Survival in breast cancer: a populationbased study in Bangalore, India. Int J Cancer 60(5): 593-596.

39. Sankaranarayanan R, Black RJ, Parkin DM (1998) Cancer survival in developing countries. IARC Sci Publ (145): 135-173.

40. Swaminathan R, Selvakumaran R, Esmy PO, Sampath P, Ferlay J, et al. (2009) Cancer pattern and survival in a rural district in South India. Cancer Epidemiol 33(5): 325-331.

41. Sankaranarayanan R, Swaminathan R (2011) Cancer survival in Africa, Asia, the Caribbean and Central America. IARC Sci Publ (162): 1-5.

42. Dhar M, Shivani R, Vijayasimha R (2010) Population based studies of cancer survival: Scope for the developing countries. Asian Pac J Cancer Prev 11(3): 831-838.

43. Ganesh B (1995) Effect of loss to follow up in estimating survival rates. Acta Universitatis Tamperensis, Ser A, University of Tampere, Tampere, Finland, Europe.

44. Matthew A (1996) Removing bias in cancer survival estimates by active follow up and information on determinants of loss to follow up. Acta Universitatis Tamperensis, Ser A, University of Tampere, Tampere, Finland, Europe.

45. Swaminathan R (2012) An evaluation of survival of cancer patients based on registry data from low or medium resource countries. Acta Universitatis Tamperensis, University of Tampere, Tampere, Finland.

46. Brenner H, Gefeller O (1996) An alternative approach to monitoring cancer patient survival. Cancer 78(9): 2004-2010.

47. Maclennan R, Muir CS, Steinitz R, Winkler A (1978) Cancer registration and its techniques, IARC Scientific Publication, Lyon, France.

48. Young JL (1991) The Hospital Based Cancer Registry, Ch. in Cancer Registration: Principles and Methods In: Jensen OM, Parkin DM, Maclennan R, Muir CS, Skeet RG (Eds.), IARC Scientific Pub, Lyon, France.

49. NCRP (National Cancer Registry Programme) (2001) Ten-year consolidated report of the hospital based cancer registries 1984-1993, Indian Council of Medical Research, New Delhi, India.

50. Howard SC, Bustos A, Carrato A (2010) Use of hospital based cancer registries to evaluate the quality of cancer care: A survey to the international community of Oncologists. Journal of Clinical Oncology 28(15): e16531.

51. Dhar M, Nandakumar A (1994) Are there any urban rural differences in cancer patterns? An attempt at looking data from the hospital cancer registries. Abstarct Book I, XVI International Cancer Congress 1994, New Delhi, India.

52. TMH (Tata Memorial Hospital) (2004) Annual Report 2000, Division of Epidemiology and Biostatistics. Tata Memorial Hospital, Mumbai, India.

53. NCRP (National Cancer Registry Programme) (2004) Development of an atlas of cancer in India-First all India report - Volume I, Indian Council of Medical Research, New Delhi, India.

54. Jedy-Agba EE, Curado MP, Oga E, Somaila MO, Ezeome ER, et al. (2012) The role of hospital-based cancer registries in low and middle income 
countries-The Nigerian case study. Cancer Epidemiology 36(5): 430435.

55. Higashi T, Nakamura F, Shibata A, Emori Y, Nishimoto H (2013) The national database of hospital-based cancer registries: A nationwide infrastructure to support evidence-based cancer care and cancer control policy in Japan. Jpn J ClinOncol 44(1): 2-8.

This work is licensed under Creative

Commons Attribution 4.0 License

DOI: $10.19080 /$ JTMP.2018.02.555594
56. Okobia MN (2013) Cancer care in sub-Saharan Africa-Urgent need for population-based cancer registries. Ethiop J Health Dev 17(2): 89-98.

57. Nandakumar A, Gupta PC, Gangadharan P, Visweswara RN, Parkin DM (2005) Geographic pathology revisited: Development of an atlas of cancer in India. Int J Cancer 116(5): 740-754.

Your next submission with Juniper Publishers will reach you the below assets

- Quality Editorial service

- Swift Peer Review

- Reprints availability

- E-prints Service

- Manuscript Podcast for convenient understanding

- Global attainment for your research

- Manuscript accessibility in different formats

( Pdf, E-pub, Full Text, Audio)

- Unceasing customer service

Track the below URL for one-step submission https://juniperpublishers.com/online-submission.php 